\title{
Student statistics programs for the Macintosh
}

\author{
RICHARD S. LEHMAN \\ Franklin \& Marshall College, Lancaster, Pennsylvania
}

\begin{abstract}
This paper reviews 15 statistics programs for the Macintosh. All are intended for student use, often in conjunction with a statistics course, and are available for under $\$ 100$. Of the general-purpose programs, Data Desk and StatView offer the most appealing combination of features, Macintosh interface, and student-accessible manual. Minitab is also recommended, especially in situations where some students will be using Macs and others using PCs. In addition to the analysis-only programs, two other applications present interesting combinations of statistics and other features. DataSim offers outstanding data generation and experiment simulation along with very complete, and psychologyoriented, statistical analysis. HyperStat combines an entire statistics textbook in hypertext format with a complete data analysis package. Finally, for special situations where simple statistics are all that are required, InStat is recommended because of its tutorial features and very simple interface.
\end{abstract}

This is a review of student statistical programs for the Macintosh. It is not a review of the large-scale "professional" statistics programs that cost several hundred dollars. All of the programs included here are available either directly to individual purchasers or through educational institutions for $\$ 100$ or less. (For recent reviews of the professional programs, see Best \& Morgenstern, 1991, and Seiter, 1993). The programs reviewed are listed in the Appendix, along with publication and pricing information. This list seems to constitute an exhaustive set of the offerings in student Macintosh category; notes placed on several Internet lists asking for omissions produced no other candidates.

The presumed audience for this review is (1) statistics instructors who are committed to the Macintosh and wish to make a program available to their students and perhaps include it in their teaching, (2) psychology students and researchers who need a statistics program but whose needs cannot justify the considerable expense of a professional program, or (3) instructors who teach in mixedcomputer environments and want to suggest a statistics program to the Mac-using students, with the hope that the PC and the Mac versions of the programs are not too different.

$\mathrm{Be}$ forewarned of two biases in the review. First, these programs are intended for student use, typically in conjunction with a statistics course. As such, the computer should not stand in the way of statistical understanding. Any program that imposes substantial new burdens and learning tasks on the student will be a hindrance rather than a help in learning statistics. Second, Macintosh users do not easily accept substitutes. A program that is

The author would like to thank Gary McClelland and three anonymous reviewers for their assistance in clarifying the presentation. Correspondence should be addressed to R. S. Lehman, Franklin \& Marshall College, Whitely Psychology Laboratories, P. O. Box 3003, Lancaster, PA 17604-3003 (e-mail: r_lehman@acad.fandm.edu). not "Mac-like" will not be tolerated well by either students or instructors. The Macintosh interface standards demand a great deal of consistency across programs; in menus, in interaction style, and in ways of dealing with graphics. Users fully acquainted with the Macintosh interface and standards will become angry and frustrated with a program that does not behave "properly."

The programs reviewed here may be categorized in several ways. First, there is a breakdown between the generalpurpose statistical applications and the special-purpose ones. General-purpose programs aim to be nothing other than statistics programs. They offer a good selection of the analyses that have come to be expected: descriptive graphics, summary statistics, transformations, two- and multiple-variable correlation and regression, ANOVA, chi-square, and the like. On the other hand, the specialpurpose programs have a different aim, but include at least a part of the common set of statistics. This review concentrates on the former group and looks only at the statistical content of the latter.

Within each category of program, there are two kinds of interface style (which, as it turns out, is directly connected to the program's origin). First is the "pure-Mac" program. These programs offer point-and-click interfaces, exceptional graphics (often with tight linkage between data displays and raw data), easy data interchange using both text files and the clipboard, and the expected Macintosh menus. The second category contains programs developed originally on a command-line interface system. Most of them have been modified to run in the Macintosh environment. Often they use menus to select analyses, but the menu choices are used to create a command line that is executed when the "OK" button is clicked. These programs also permit direct use of the commandline window, allowing the user to choose between the two interface modes. These programs generally offer more difficulties in data interchange, "non-Mac" graphics, and little or no linkage between data and displays. (The exception to these statements is Stata, which was 
moved to the Macintosh but retains its command-lineonly interface.)

\section{GENERAL-PURPOSE PROGRAMS}

There are 11 programs in this group. All offer a reasonable selection of descriptive statistical procedures, most offer frequency histograms and scatterplots for graphics, bivariate and multivariate correlation and regression, and one- and two-way ANOVAs. All offer the ability to enter data via the keyboard or from text files. Many can use the clipboard to move data both in and out of the program. Since these are all "student" programs, most include some restriction on numbers of cases, variables, data points, analyses, and/or saving or printing output or data.

The basic features of the programs are summarized in Tables 1-3. Table 1 describes the general mechanics of the programs, including the system requirements, restrictions, installation, and features of the manual. Table 2 describes some of the input and output attributes of each program. The coverage of the common elementary statistics is noted in Table 3. Additional features of each program are described below.

All of the programs were checked for computational accuracy (see Best \& Morgenstern, 1991, and Lehman, 1986,1988 , for details on the testing). Given the numerical accuracy offered by Apple's SANE (Standard Apple Numeric Environment) package and the sophistication of the program development environments now available for the Macintosh, few accuracy problems were expected. Surprisingly, several were found and are noted below. These errors suggest that some of the programs employ outdated, "desk calculator" formulas rather than newer and more accurate algorithms.

\section{Data Desk Student Version}

Features. One of the earliest of the Macintosh statistics programs, Data Desk consistently receives very strong support from reviewers. It is highly interactive and virtually forces the user to explore the data. It offers a very wide array of features and a very consistent Macintosh interface. Data and graphics are tightly linked, so that brushing and other selections in a graphics window show up immediately in the raw data and in all other graphic displays. A very wide range of descriptive and inferential techniques is offered. All classical hypothesis tests are available. The random-number-generation facilities are exceptional and allow many creative ways for an instructor to develop simulations. All graphics are flexible and allow easy click-and-drag adjustments and easy copying to other applications. Regression is a particularly strong feature, with extensive tools for residuals analysis available. An interesting feature is the ability to use the output of one analysis as input for another analysis (e.g., a set of means of randomly generated samples can be used as input to a histogram, providing a look at a "sampling distribution"). Many of Data Desk's displays and variables are "live," meaning that changing a data value or a selection results in updates to all displays and representations. Pop-up menus offer a large number of additional and related analyses (e.g., a pop-up menu on a scatterplot offers to locate the variables, to insert the regression line, or to compute the correlation or regression).

The manual/textbook that accompanies Data Desk is worthy of special mention. It is exceptionally well written, and provides a great deal of information about statistics and data analysis, as well as teaching and illustrating how to use the program.

Data Desk's accuracy is beyond reproach.

Weaknesses. All of the tested programs have some annoying features. Data Desk has two. The first stems directly from its data structure: simple data editing and entry can be confusing and error prone. Worse, variables having different numbers of observations can be particularly troublesome and frustrating to newcomers to the program (and to old hands as well). Second, nearly every operation produces at least one new window (or variable, or relationship, or bundle, or folder), resulting in severe screen clutter very quickly.

\section{JMP-IN}

Features. The program is organized in terms of "platforms" where various analyses are conducted. In defining and using the platforms, the program takes the level of measurement very seriously and perhaps to extreme. Choosing the "Fit Y by X" platform, for example, performs one of four different analyses, depending upon whether $\mathrm{Y}$ and $\mathrm{X}$ are normal, ordinal, or interval/ratio. You can change the measurement level of a variable easily, but perhaps so much importance should not be attached to them in the first place (see Velleman \& Wilkinson, 1993).

JMP-IN is highly accurate. Unfortunately, some of the tests (those aimed at determining the precision of the computations) indicated that the program's designers had allowed insufficient space on the output screen for very large and very small values. Tests with singular matrices produced informative regression output indicating that there were accuracy problems, but no possible causes were suggested.

The program leaves little to be desired in terms of analyses offered. A very large number of analyses are presented automatically, once a computation platform and variables are chosen. However, a first-course instructor will frequently have to tell students to ignore much of what the program offers, since nearly every analysis screen offers results that no beginning course, or many advanced courses for that matter, needs to know about.

Weaknesses. JMP IN's manual is complete, but cryptic and specialized in its vocabulary. It uses terminology and graphic displays that will be foreign to many psychologists. The manual does not explain the meaning of many of the outputs in enough detail to explain them to someone unfamiliar with the techniques and approach to data analysis offered by the program. Some users or in- 


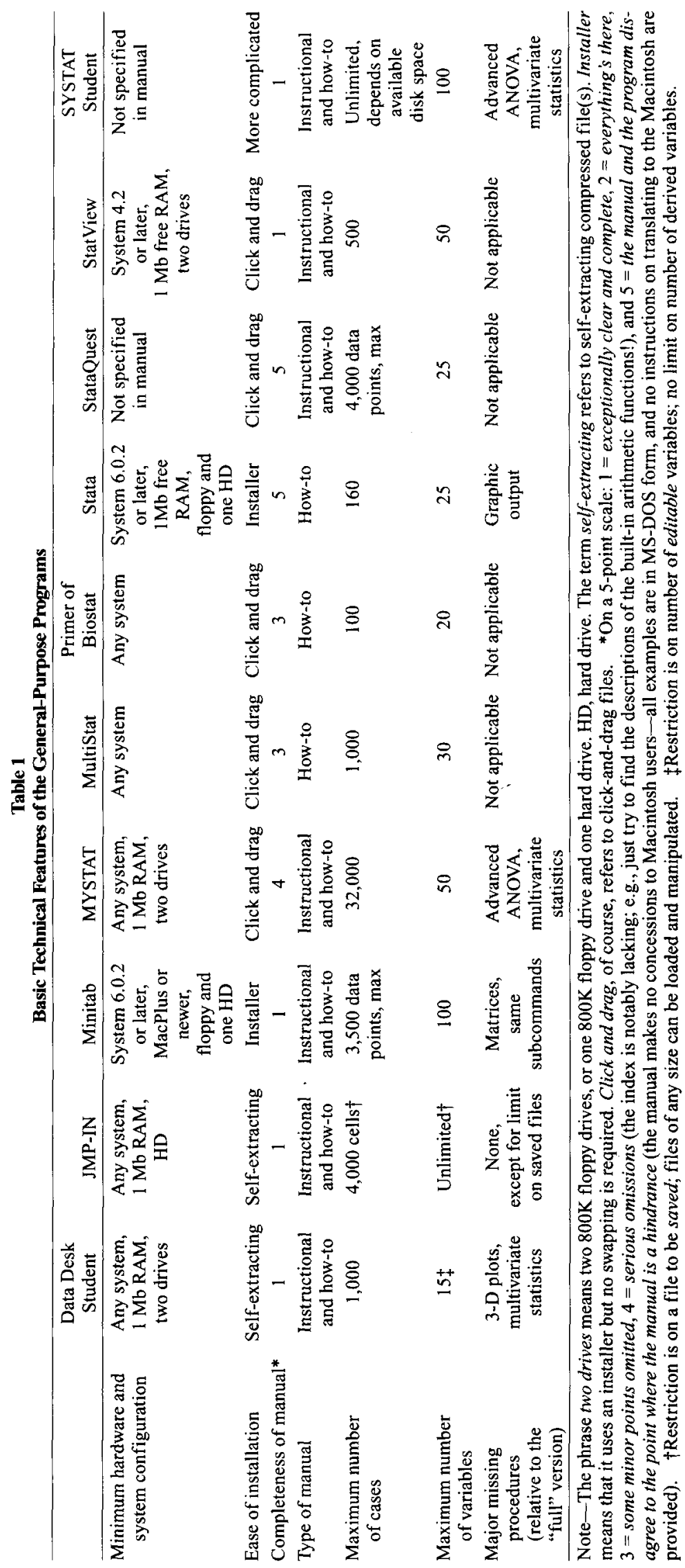


Table 2

Input/Output Characteristics of the General-Purpose Programs

\begin{tabular}{|c|c|c|c|c|c|c|c|c|c|c|}
\hline & Data Desk & JMP-IN & Minitab & MultiStat & MYSTAT & Primer & Stata & StataQuest & StatView & SYSTAT \\
\hline Interface type & Mac & Mac & $\mathrm{M}-\mathrm{CLI}^{\mathrm{a}}$ & $\mathrm{Mac}$ & M-CLI & Mac & CLI & M-CLI & Mac & $\mathrm{M}-\mathrm{CLI} \mathrm{I}^{\mathrm{a}}$ \\
\hline Numeric input from clipboard & $\mathrm{Y}$ & $\mathrm{Y}$ & $\mathrm{Y}$ & $\mathrm{Y}$ & Y & $\mathrm{N}$ & $\mathrm{N}$ & $\mathrm{N}$ & $\mathrm{Y}$ & $\mathrm{Y}$ \\
\hline Numeric output to clipboard & $\mathrm{Y}$ & Y & $\mathrm{Y}$ & $\mathrm{Y}$ & $\mathrm{Y}$ & $\mathrm{N}$ & $\mathrm{N}$ & $\mathrm{N}$ & $\mathrm{Y}$ & $\mathrm{Y}$ \\
\hline Numeric input from text file & $\mathrm{Y}$ & $\mathrm{Y}$ & $\mathrm{Y}$ & $\mathrm{Y}$ & $\mathrm{Y}$ & $\mathrm{Y}$ & $\mathrm{Y}^{\mathrm{b}}$ & $\mathrm{Y}^{\mathrm{b}}$ & $\mathrm{Y}$ & $\mathrm{Y}$ \\
\hline Numeric output to text file & $\mathrm{Y}$ & $\mathrm{Y}$ & $\mathrm{Y}$ & $\mathrm{Y}$ & $\mathrm{Y}$ & $\mathrm{Y}$ & $\mathrm{Y}$ & $\mathrm{Y}$ & Y & $\mathrm{Y}$ \\
\hline File $\mathrm{I} / \mathrm{O}^{c}$ & $\mathrm{Y}$ & $\mathrm{Y}$ & Y & $\mathrm{N}^{\mathrm{d}}$ & $\mathrm{Y}$ & $\mathrm{N}$ & $\mathrm{Y}$ & $\mathrm{Y}$ & $\mathrm{Y}$ & $\mathrm{Y}$ \\
\hline Graphics to clipboard & $\mathrm{Y}$ & Y & $\mathrm{Y}$ & $\mathrm{Y}$ & $\mathrm{Y}$ & $\mathrm{N}$ & $\mathrm{N}$ & $\mathrm{N}$ & $\mathrm{Y}$ & $\mathrm{Y}$ \\
\hline Graphics to PICT file & $\mathrm{N}$ & $\mathrm{N}$ & $\mathrm{Y}$ & $\mathrm{N}$ & $\mathrm{N}$ & $\mathrm{Y}^{\mathrm{e}}$ & $\mathrm{N}$ & $\mathrm{N}^{\mathrm{f}}$ & $\mathrm{N}$ & $\mathrm{N}$ \\
\hline
\end{tabular}

Note-Y, yes; N, no; Mac, full Mac; M-CLI, modified command line (see text); CLI, command line (several of the command-line programs have new, more "Mac-like," versions under development). a Command-line instructions are required for some operations. bFile must be in the Stata (or StataQuest) folder, named with a ".raw" suffix, and the name typed (i.e., there is no file selection dialog). cThis means that the program uses its own file storage in addition to any other method (e.g, ASCII files). dWrites only single-variable text files. eOnly by capturing a screen image. ${ }^{\mathrm{f}}$ Graphics are saved in a special format and can only be printed; no editing is possible.

Table 3

Basic Statistics Offered by the General-Purpose Programs

\begin{tabular}{|c|c|c|c|c|c|c|c|c|c|c|}
\hline & Data Desk & JMP-IN & Minitab & MultiStat & MYSTAT & Primer & Stata & StataQuest & StatView & SYSTAT \\
\hline$\overline{\text { Mean }}$ & $Y$ & $\mathrm{Y}$ & $Y$ & $Y$ & $Y$ & $\mathrm{Y}$ & $\mathrm{Y}$ & $\mathrm{Y}$ & $Y$ & $\mathrm{Y}$ \\
\hline Median & $\mathrm{Y}$ & $\mathrm{Y}$ & $\mathrm{Y}$ & $\mathrm{Y}$ & $Y^{a}$ & $\mathrm{Y}$ & $\mathrm{Y}$ & Y & Y & Y \\
\hline Standard deviation & $\mathrm{Y}$ & $\mathrm{Y}$ & $Y$ & $\mathrm{Y}$ & $\mathrm{Y}$ & $\mathrm{Y}$ & $\mathrm{Y}$ & Y & $\mathrm{Y}$ & Y \\
\hline Variance & Y & $\mathrm{N}$ & $\mathrm{Y}$ & Y & Y & $\mathbf{N}$ & Y & $Y$ & $\mathrm{Y}$ & $\mathrm{Y}$ \\
\hline Frequency table & Y & $\mathrm{N}$ & Y & $\mathrm{N}$ & $\mathrm{N}$ & $\mathbf{N}$ & $Y^{b}$ & $Y$ & Y & $\mathrm{Y}$ \\
\hline Histogram & $\mathrm{Y}$ & $\mathrm{Y}$ & $\mathrm{Y}$ & $\mathrm{Y}$ & $\mathrm{Y}$ & $\mathrm{N}$ & $\mathrm{Y}$ & $\mathrm{Y}$ & Y & $\mathrm{Y}$ \\
\hline Set intervals? & $\mathbf{Y}$ & $\mathrm{Y}$ & $\mathrm{Y}$ & $\mathrm{Y}$ & $\mathrm{Y}$ & - & $\mathrm{N}$ & $\mathrm{Nc}$ & $\mathrm{Y}$ & $\mathrm{N}$ \\
\hline Set start point? & $\mathrm{Y}$ & $\mathbf{N}$ & $Y$ & $\mathrm{Y}$ & Y & - & $\mathrm{N}$ & $\mathrm{N}^{\mathrm{c}}$ & $\mathrm{Y}$ & $\mathrm{Y}$ \\
\hline Transformations ${ }^{\mathrm{d}}$ & $\mathrm{Y}$ & Y & Y & Y & Y & $\mathrm{N}$ & Y & $\mathrm{Y}$ & $\mathrm{Y}$ & $\mathrm{Y}$ \\
\hline Random numbers & $\mathrm{Y}$ & $\mathrm{Y}$ & $\mathrm{Y}$ & $\mathrm{Y}$ & $\mathrm{Y}$ & $\mathrm{N}$ & $\mathrm{Y}$ & $\mathrm{Y}$ & $\mathrm{Y}$ & Y \\
\hline One sample $z$ & $\mathrm{Y}$ & $\mathbf{N}$ & $\mathrm{Y}$ & $\mathrm{N}$ & $\mathrm{N}$ & $\mathrm{N}$ & $\mathrm{N}$ & $\mathrm{N}$ & $\mathrm{N}$ & $\mathrm{N}$ \\
\hline One sample $t$ & $\mathrm{Y}$ & $\mathrm{Y}^{\mathrm{e}}$ & $\mathrm{Y}$ & $\mathrm{N}$ & $\mathrm{N}$ & $\mathrm{N}$ & $\mathrm{N}$ & $Y^{e}$ & $\mathrm{Y}$ & $\mathrm{N}$ \\
\hline Two sample $z$ & Y & $\mathrm{N}$ & $\mathrm{Y}$ & $\mathrm{N}$ & $\mathrm{N}$ & $\mathrm{N}$ & $\mathrm{N}$ & $\mathrm{N}$ & $\mathrm{N}$ & $\mathrm{N}$ \\
\hline Pooled $t$ & $\mathrm{Y}$ & $\mathrm{N}^{\mathrm{f}}$ & $\mathrm{Y}$ & $\mathrm{Yg}^{\mathrm{g}}$ & $\mathrm{Y}$ & $\mathrm{Y}$ & $\mathrm{Y}$ & $\mathrm{Y}$ & $\mathrm{Y}$ & Y \\
\hline Unequal $\sigma^{2} t$ & $\mathrm{Y}$ & $\mathrm{N}$ & $\mathrm{Y}$ & $\mathrm{N}$ & Y & $\mathrm{N}$ & $\mathrm{Y}$ & $\mathrm{Y}$ & N? & $\mathrm{Y}$ \\
\hline Matched pairs $t$ & $\mathrm{Y}$ & $\mathrm{Y}^{\mathbf{h}}$ & $\mathrm{Y}$ & $\mathrm{Y}$ & $\mathrm{Y}$ & $\mathbf{Y}$ & $\mathrm{Y}$ & $\mathrm{Y}$ & $\mathrm{Y}$ & $\mathrm{Y}$ \\
\hline One-way ANOVA & $\mathrm{Y}$ & $\mathrm{Y}$ & $\mathrm{Y}$ & $Y^{i}$ & $\mathrm{Y}^{\mathrm{j}}$ & $\mathrm{Y}$ & $\mathrm{Y}$ & $\mathrm{Y}$ & $\mathrm{Y}$ & $\mathrm{Y}$ \\
\hline Factorial ANOVA & $\mathrm{Y}$ & $\mathrm{Y}$ & $\mathrm{Y}$ & $\mathrm{Y}$ & $\mathrm{Y}$ & $\mathrm{N}$ & $\mathrm{Y}$ & Y & Y & $\mathrm{Y}$ \\
\hline Bivariate correlation & $\mathrm{Y}$ & $\mathrm{Y}$ & $\mathrm{Y}$ & $\mathrm{Y}$ & $\mathrm{Y}$ & $\mathrm{Y}$ & $\mathrm{Y}$ & $\mathrm{Y}$ & $\mathrm{Y}$ & $\mathrm{Y}$ \\
\hline Bivariate regression & $\mathrm{Y}$ & $\mathrm{Y}$ & $\mathrm{Y}$ & $\mathrm{Y}$ & $\mathrm{Y}$ & $\mathrm{Y}$ & $\mathrm{Y}$ & $\mathrm{Y}$ & $\mathrm{Y}$ & $\mathrm{Y}$ \\
\hline Multiple regression & $\mathrm{Y}$ & $\mathrm{Y}$ & $\mathrm{Y}$ & $\mathrm{Y}$ & $\mathrm{Y}$ & $\mathrm{N}$ & $\mathrm{Y}$ & $\mathrm{Y}$ & $\mathrm{Y}$ & $\mathrm{Y}$ \\
\hline Sorting/ranking & $\mathbf{Y}$ & $\mathrm{Y}$ & $\mathrm{Y}$ & $\mathrm{Y}$ & $\mathrm{Y}^{\mathrm{k}}$ & $\mathrm{N}^{1}$ & $\mathrm{Ym}_{\mathrm{m}}$ & $\mathrm{Y}$ & $\mathrm{Y}$ & $\mathrm{Y}^{\mathrm{n}}$ \\
\hline
\end{tabular}

Note-Y, yes; N, no. a Median is available only in a stem-and-leaf display. ${ }^{b}$ For categorical variables only. ${ }^{c}$ Only choice is setting number of score variables. dProgram provides for defining new variables as functions of existing ones; a reasonable set of common functions is provided. eOnly for $\mu=0$. ${ }^{\mathrm{f}}$ Not directly; the $t$ test is a part of the "Fit Y by X" platform, and appears as an analysis of variance with two conditions. gOutput gives a probability value, but $d f \mathrm{~s}$ are not reported. hOnly for a variable that is separately computed to be the difference between two other variables; the default test of $\mu=0$ is then carried out. iProgram shows severe loss of accuracy in the ANOVA test with five digit values differing in only the last two significant digits. jFor ANOVA, all data must be in one column with group codes in a second column. Interestingly, sign tests and Friedman nonparametric ANOVA will accept data in separate columns. kSorted data go to a new file. IBut a large number of nonparametric tests using ranks are offered. mSorting only; no ranking function is provided. ${ }^{\mathrm{n} S o r t e d}$ or ranked data go to a new file.

structors may dislike having all of their choices made for them on the basis of assumptions made by the programmers' data analysis philosophy.

JMP IN may be too much program, too little manual, with much too little freedom of choice to satisfy most psychologists/teachers.

\section{Minitab}

Features. Many psychologists grew up learning Minitab in its command-line form. Those who have not investigated the program recently will have a pleasant surprise. First, it is much improved, especially in the ANOVA area. Second, the Macintosh version is exceptionally well done. Third, the data editing is made much easier by using a spreadsheet interface that makes all data in all columns easily available.

Using Minitab's menus constructs command-line instructions and an "OK" button conducts the analysis. The familiar Minitab command-line interface is still available (but remains optionally hidden) and in fact is necessary for a few advanced analyses. A very important feature - the STORE command-is preserved, allowing the user to create macros. Prewritten macros can be used from within the program; given the extensive library of macros available through the Minitab User Group, this is a powerful feature of the program.

Numerous books include Minitab commands and output in their presentation, and having the program avail- 
able for the Macintosh will be very helpful for instructors and students using such texts.

All of Minitab's features and analyses (except matrices) are present, though some of the advanced subcommands for regression, GLM, and ANOVA are omitted from the student version. All graphics commands produce "hi-res" graphics (i.e., they generate Minitab's "G..." commands), and all graphics may be moved to the clipboard.

Minitab's accuracy is adequate. Some numeric and graphic displays suffer when very large or very small values are presented (spacing/labeling may be destroyed and/or digits lost when the program shifts to exponential notation). Internal accuracy is perfect with values of seven or fewer significant digits. Singular matrices produce correct and informative comments in regression.

Weaknesses. There are few weaknesses to Minitab. It is a well-known program and has aged well. It made the transition to the Macintosh satisfactorily, though Mac purists will complain that its CLI is still too evident and in fact is needed for some operations. Some instructors have been heard bemoaning the loss of matrix operations in the student version.

The displays are static, and there is no linkage between graphics and other data displays.

\section{MultiStat}

Features. This is a rewrite of an older program (STATPACK) for the Macintosh. It presents a fully menu-driven Macintosh interface, but it looks crude and (for the Mac) strangely quaint.

Weaknesses. Multistat's design is simplistic, and its statistical offerings are very limited relative to others in this group. The graphics are inadequate when compared with those of, say, Data Desk, and there is no linkage between graphic and tabular presentations of the data.

MultiStat showed serious inadequacies during testing. A data set containing no valid cases (i.e., no case had data on all variables) produced believable-looking regression output with nothing but a statement about unequal column lengths as an indication of error. In addition, data containing five or more significant digits produced a one-way ANOVA summary table without a single correct value.

\section{MYSTAT}

Features. This program is a stripped-down version of SYSTAT, adapted to the Macintosh. In most cases, it is cumbersome to use. Its command-line interface is barely hidden behind the pull-down menus.

MYSTAT's accuracy is fine, though very large and very small values show loss of precision on the screen display.

Weaknesses. While MYSTAT seems to have numerous features, it is highly frustrating and aggravating in actual use. Most annoying of all are the graphics, which steadfastly refuse to be edited in any meaningful way. Histograms are constructed with the proportion of values on the left axis and frequency on the right; it is impossible to change those designations. To compare vari- ables using box plots, you must draw an invisible box on the screen where you want the next plot to appear; otherwise, all box plots are simply overlaid. Even data editing is complicated in that it is impossible to change just a single digit in a data value. While the data are in spreadsheet form, clicking in a cell selects the entire cell and the whole value must be re-entered; no intracell cursor is available.

\section{StatView}

Features. This is a popular program for the Macintosh. Along with Data Desk, its professional version is uniformly highly rated. Data entry is simple and obvious, using a spreadsheet format. Analyses are selected by first choosing one or more columns and then selecting an analysis from a menu. All of the expected analyses are present, though ANOVA is limited to only oneand two-way designs; the authors apparently believe that the publisher's SuperANOVA program will be used for anything else. Bivariate and multiple regression is complete (including polynomial regression up to order 9), but fewer residual features are offered than are present in Data Desk.

StatView's accuracy is beyond reproach. The error messages resulting from singular matrices in regression are exceptionally informative.

Weaknesses. All programs require that you select an "X" or a " $Y$ " variable before they complete an analysis. In StatView, forgetting to do so produces an empty window saying "You have not chosen an X column," a slight annoyance. Worse, you must "deselect" all "X"s and "Y"s before selecting new ones. If you forget, the new columns are simply added to the previous selections. Perhaps a more serious annoyance with StatView is that it copies all output windows to the clipboard as graphics; to get the regression summary table or other numeric values into another program for editing, the values must be retyped.

Graphic displays are not linked to data and computation windows, and there are no pop-up menus or "hot" links between analyses.

\section{Primer of Biostatistics}

Features. This is a simple little program with a large number of elementary tests offered. It offers the most extensive set of power computations of any of the reviewed programs. Its accuracy is good, with precision limited only by the size of the display. ANOVA with unequal sample sizes is handled by using a weighted means procedure, although there is nothing that tells the user that fact. Repeated measures ANOVA is offered. A good set of pairwise ANOVA follow-up tests is offered for both repeated measures and independent groups.

Using the program is simplicity itself. Select the statistic you want, enter the data or use what's already there (when running an ANOVA follow-up, for example), or read it from a text file, then click on "Execute."

Output cannot be captured to the clipboard, but screen output can be directed to an output spool for printing. 
Weaknesses. More than anything else, this attractive little program suffers from lack of features. While a long list of statistics appears when the "Select Analysis" menu item is chosen, the offerings are all quite elementary. Any ANOVA beyond one way is unavailable. Multiple regression is not offered. Graphics, except for an uneditable scatterplot for correlation, are nonexistent. There are no provisions for data transformations, nor does the program accept clipboard input except for a single value at a time. Editing individual data values is awkward because no intracell cursor is available-you must re-enter the entire value. There are no graphic displays for univariate data analysis.

\section{Stata}

Features. Stata has strong advocates in the PC world, where it is highly regarded. But its Mac version is a throwback to earlier days in computing. The conversion from command-line to Mac interface is effectively nonexistent. Entering Stata leads to a prompt character, and from there on only typed commands are available. There are no restrictions on the size of a data set.

Weaknesses. Stata has graphics but refuses to allow any graphics output other than to the screen. (Even screen utilities seem unable to capture Stata's graphics.) The menus that are present have little effect-or at least not the expected effect-and, in any event, are unexplained in the manual.

The program is saddled with a very terse and confusing manual, where terms like Mac, Macintosh, Menu, and clipboard do not even appear in the index, and all examples and file names are in MS/DOS form.

The program showed serious inaccuracy with data values containing over four digits during ANOVA testing. The program also showed problems in regression testing, where the singular matrix tests produced output that a novice could mistake easily for valid output. (In fact, variables were simply dropped from each analysis, but the output describing that fact is easy to overlook.)

Stata cannot be counted as a serious contender in the Macintosh student statistics package race. It might conceivably be useful in a setting where Stata on PCs is being taught and Mac-using students are thereby disadvantaged; at least, the command-line interfaces are (apparently) identical. (StataQuest-see below-is a far better option in this situation.)

\section{StataQuest}

Features. This version of the Stata program is an attempt to produce a version of the program that operates identically on both Mac and PC machines so that it could be bundled with textbooks. The programmers achieved that goal, but the result is an exceptionally confusing application. The program offers a great many features and advanced options; it would be a good choice for both introductory and intermediate statistics students were it not for the interface. StataQuest's accuracy is acceptable, an improvement over Stata (see above), except that singular matrices in multiple regression may produce out- put that can easily be accepted as correct since no warnings are given.

Weaknesses. StataQuest's interface is an odd blend of menus and command lines and is destined to be confusing to Mac-familiar students. Data may be edited in a spreadsheet-like form, but no intracell cursor is available. The manual, while complete in describing the program, does not offer any assistance for the Mac user; instructors who opt to use this program will have to provide handouts and other help. Text file input is very awkward-the clipboard is nonfunctional, and data must be in especially prepared files and stored in the same folder as the program. Graphics are extremely limited and crude.

\section{SYSTAT Student}

Features. This program is a step up from MYSTAT in size and apparent capability and seems to be a rewrite of an earlier SYSTAT, Inc. product known as FASTAT.

Weaknesses. Unfortunately, all of the difficulties that plague MYSTAT surface again in SYSTAT. In addition, there are serious errors in the manual. For example, the instructions for opening a saved SYSTAT file simply do not work; an empty screen is the only result. SYSTAT had by far the most difficult installation of any program reviewed, even given the written instructions in the manual.

On all of the singular matrix tests for multiple regression, Student SYSTAT simply cleared the Analysis window (where results should appear); there were no diagnostic messages. Otherwise, all accuracy testing was satisfactory.

\section{Recommendations on the General-Purpose Programs}

For instructors who are searching for a generalpurpose program in a Macintosh environment and/or are committed to having a "real" Mac program for their students, the choice is between Data Desk and StatView. Both are excellent examples of the Macintosh interface at work, though they take very different approaches to its use. Both offer excellent data handling, graphics, and inferential tests. Data Desk has an advantage in linking graphics and data, in the array of procedures and options available, and in its manual. StatView is easier to use because of its spreadsheet data arrangement but is considerably less versatile. JMP-IN is in a somewhat distant third place, primarily because of its idiosyncratic style in text and graphics. It is also less desirable because of its manual, which assumes far too much of the beginning student (and his or her instructor). MultiStat is simply too old and too expensive to be of much value in an educational environment.

An instructor might choose one of the converted command-line programs in a mixed environment where some students would be using Macs and others PCs. In this case, Minitab is an excellent choice, especially if it is available on a mainframe, PC, or UNIX system in command-line mode. The other programs in the group conflict with both of the two biases cited above: they would interfere with learning the statistical content of the course, 
and they do not feel like "proper" Macintosh programs. SYSTAT, MYSTAT, or StataQuest might be recommended in a mixed PC environment but are "odd" in terms of their ability to handle graphics, and Mac-committed students will not like them. StataQuest should be considered only where nearly all of the class would be using a $\mathrm{PC}$, where the instructor is committed deeply to the program, and where the instructor is prepared to spend considerable time with the Mac-using students to overcome the weaknesses of the manual.

MYSTAT has been promoted aggressively by its inclusion in several books, as well as a stand-alone book/ program combination at a very reasonable price. In general, though, for a Macintosh environment, MYSTAT can be recommended only where price is the sole object. (Students can pay less than double MYSTAT's nominal price and get the far-superior Data Desk.)

\section{SPECIAL-PURPOSE PROGRAMS}

This is an interesting collection of software. The first hypertext statistics book is here, along with two programs intended to teach students how to look at data analyses, both especially geared to simulations of research models. In addition, two restricted data analysis programs are here. One does nothing but ANOVA (and does it very well). The other offers a very small set of analyses, but does so in a very informative way that could be exceptionally useful in laboratories where statistics users may have had minimal formal instruction.

Formal accuracy testing was not carried out on these programs, but simple checks showed that they performed adequately on the analyses that they offer.

\section{CLR ANOVA}

After a word processor, this may be the psychologist's most popular Macintosh program. It does analysis of variance, and nothing else. It has no data editor (relying on external data preparation), relatively crude graphics (although what it has are very important), almost no descriptive statistics, no least-squares option for unequal groups sizes, and a quirky, idiosyncratic interface. Why, then, is it so popular? Because it will carry out ANOVA computations for any fully factorial design with up to five between-subjects factors and up to five within-subjects factors. As for descriptive statistics, it computes only cell means. It offers a range of follow-up tests (simple effects, $t$ tests, Tukey, Newman-Keuls, and Duncan). Importantly, the program plots interactions to aid in interpretation. Many research laboratories would find it difficult to function without this program. It is included here just in case there is someone who does not know of it.

The newest version of CLR ANOVA includes a Hypercard front-end to the program, which somewhat eases the preparation of data and the description of the experimental design.

\section{DataSim}

This program was moved to the Macintosh from the $\mathrm{PC}$, and so suffers from a multiple personality similar to that of Minitab. There are a few remaining flaws in the program, and a Mac user will feel less "at home" here than in some of the other programs. DataSim was originally written to simulate a large number of "classic" experiments in psychology, allowing students to rerun them as class exercises. The program now is much broader, allowing extensive statistical analysis, as well as simulated sampling in support of virtually any research design. A particular strength is the program's ability to generate data from completely specified univariate and multivariate distributions. DataSim is unique in this ability and allows the instructor to generate and illustrate a very large number of statistical phenomena.

The data analysis segment of DataSim is very extensive, with a large variety of tests and statistics available. The graphics capabilities are complete if not terribly sophisticated, including scatterplots, interaction graphs, and other displays. Graphics may be copied for use in other programs, but there is no linkage between graphic displays and raw data.

An instructor might choose to use DataSim as a complete laboratory and data analysis package for a course. This would allow the students to rerun classic experiments from the provided library, design their own experiments and "run" them using the simulation capabilities of the program, experiment with statistical distributions, or use DataSim just as a statistical analysis system. In the latter case, one of the general-purpose programs might serve, though the ANOVA capabilities here are considerably above those of, for example, StatView. DataSim could also be useful in a mixed-computer environment, since both PC and Mac versions are available. It is a great deal more appealing for such use than, say, Student SYSTAT or StataQuest.

\section{HYPERSTAT}

This is a real novelty. It is a complete introductory statistics textbook and a very complete statistical analysis program, all written for use with Hypercard. The instructional and text material seems adequate if not exceptional when compared with existing texts, though several somewhat unusual and recently developed analyses are discussed (resampling tests, for example). It would be interesting to know how the material would actually serve as the sole textbook for a course, which is clearly its intent.

The statistical content of the program (actually a Hypercard stack) offers a complete data analysis environment, comparable to the general-purpose programs described previously. In fact, the whole of CLR ANOVA is included in HyperStat-they were written by the same author. Since the entire statistical system is embedded within Hypercard, the analysis can be cumbersome, with considerable clicking on buttons and moving from 
screen to screen. In addition, Hypercard computation is significantly slower than in dedicated statistics programs. The program's accuracy is acceptable.

Adventurous instructors might wish to try this hypertext approach to teaching statistics or, alternatively, consider it as a supplement to a more standard textbook, since it offers a very good analysis framework and closely linked, well-written theoretical and explanatory material.

A separate review of HyperStat has appeared in this journal (Brooks, 1994). It covers the program in considerably more detail.

\section{InStat}

This is a clever and well-written little program. It has a limited audience, but, for that audience, it may be an ideal program. InStat was not included among the generalpurpose programs because its selection of statistics and analyses is simply too limited to be useful in a statistics course.

InStat offers only three kinds of analysis: (1) "column comparisons" (Student's $t$, one-way ANOVA, and descriptive statistics), (2) contingency table analysis, and (3) bivariate correlation/regression. In every case, several techniques are offered, both parametric and nonparametric. While this restriction on kinds of analyses is severe in terms of what a statistics instructor might require, the offerings are nearly perfect for many research laboratories.

If you need only the analyses in this program, InStat is a small gem. Why? First is the interface. It is absolutely manual-free. Once the kind of analysis is chosen, the program offers a step-by-step (actually, icon-byicon) procedure, leading to the results. Data can be reviewed, saved, and edited at any time; output can be printed, with or without added notes. The second exceptional feature of the program are the "Theory" and "Interpret" buttons that are nearly always present. Each leads to a concise, clear, and accurate description of the theory underlying an analysis or the proper interpretation of the results. Anyone thrown into a laboratory without a course in statistics (or perhaps with rusty knowledge) can learn a great deal from the information offered.

InStat would be ideal in a laboratory course where some of the students had not completed a prerequisite statistics course, for those who have forgotten nearly all of their statistics, or for statistically naive technicians who simply need to obtain results quickly and easily.

\section{Models ' $n$ ' Data}

Here is another unique approach to statistics software. This program was intended to support courses where the emphasis is on fitting models to data. It presents a wide variety of procedures for defining models, generating samples from them, and testing various fits to the models. The program can also be used for elementary data analysis, but doing so is cumbersome. No more than three variables are permitted in any analysis. The program is excellent for its intended purpose, but it cannot be recommended for data analysis beyond that required in a course that might be developed specifically around this material.

\section{Recommendations on the Special-Purpose Programs}

There are three programs in this group that offer interesting new ways to package a statistics course or sequence. HyperStat presents the option of putting all of the material into a hypertext format, though the statistics textbook that forms a part of the Hypercard stack is organized traditionally into chapters. Students can be assigned chapters as with an ordinary textbook, but the option of hypertext is always available for them to use in exploration. The statistics package itself will be more than adequate for most first-course students. DataSim offers another very interesting possibility to the instructor. Here is a complete experiment description/simulation/analysis system in an easy-to-use and compact package. While its conversion to the Macintosh interface is far from perfect and students may soon learn to use the command lines, it is well worth consideration. Finally, Models ' $n$ ' Data offers the possibility of a course built entirely around a modelselection approach to teaching. While this way of looking at statistics is foreign to most psychologists, it is current among mathematicians.

CLR ANOVA and InStat offer a different kind of power to the instructor. Anyone who has struggled to teach complex ANOVA computations to undergraduates may appreciate the opportunity to "let the computer do the arithmetic." With CLR ANOVA, you can do just that; the program is an automated Keppel (1991). InStat may provide just the solution that a laboratory instructor is looking for in a simple computational package. It provides the added benefit of excellent tutorials on everything it does.

\section{REFERENCES}

Best, A. M., \& MoRgenstern, R. (1991). Statistics programs designed for the Macintosh: Data Desk, Exstatix, Fastat, JMP, StatView II, and SuperANOVA. American Statistician, 45, 318-338.

Brooks, J. O., III (1994). HyperStat: A statistical toolbox for the Macintosh. Behavior Research Methods, Instruments, \& Computers, 26, 470-474.

KEPPEL, G. (1991). Design and analysis: $A$ researcher's handbook (3rd ed.). Englewood Cliffs, NJ: Prentice-Hall.

LeHMAN, R. S. (1986). Macintosh statistical packages. Behavior Research Methods, Instruments, \& Computers, 18, 177-187.

Lehman, R. S. (1988, July). Macintosh statistical packages. Byte, 12, 207-214.

SeITER, C. (1993, October). The statistical difference. MacWorld, 9 , 116-121.

Velleman, P. F., \& Wilkinson, L. (1993). Nominal, ordinal, interval, and ratio typologies are misleading. American Statistician, 47, 65-72. 


\begin{tabular}{|c|c|}
\hline \multicolumn{2}{|c|}{$\begin{array}{c}\text { APPENDIX } \\
\text { Reviewed Software }\end{array}$} \\
\hline CLR ANOVA & Primer of Biostatistics \\
\hline Clear Lake Research, Inc. & McGraw-Hill Publishing Company \\
\hline 2476 Bolsover STE 343 & ISBN: 0-07-864l15-2 \\
\hline Houston, TX 77005 & $\$ 65$ \\
\hline \multicolumn{2}{|l|}{$\$ 37.50($ minimum of 10$)$} \\
\hline DataSim & Duxbury Press, Inc. \\
\hline DeskTop Press & ISBN: 0-534-18919-9 \\
\hline 90 Bardwell St. & $\$ 28.50$ \\
\hline \multicolumn{2}{|l|}{ Lewiston, ME 04240} \\
\hline \multirow[t]{2}{*}{$\$ 55$} & StataQuest \\
\hline & Duxbury Press, Inc. \\
\hline HYPERSTAT & ISBN: $0-534-23677-4$ \\
\hline Academic Press, Inc. & $\$ 14$ \\
\hline ISBN: $0-12-436130-7$ & (also bundled with some texts) \\
\hline \multicolumn{2}{|r|}{ (a) } \\
\hline & StatView (student version) \\
\hline InStat & Abacus Concepts \\
\hline GraphPad Software & 1918 Bonita Ave. \\
\hline 10855 Sorrento Valley Rd., \#203 & Berkeley, CA 94704-1014 \\
\hline San Diego, CA 92121 & $\$ 66($ minimum of 10$)$ \\
\hline$\$ 45$ (minimum of 10 ) & Student Data Desk \\
\hline JMP-IN & W. H. Freeman, Inc. \\
\hline Duxbury Press, Inc. & ISBN: $0-7167-2201-1$ \\
\hline ISBN: $0-534-20544-5$ & $\$ 28$ \\
\hline \multicolumn{2}{|l|}{$\$ 30$} \\
\hline & Student Minitab \\
\hline Models 'n' Data & Addison-Wesley \\
\hline Intellimation, Inc. & ISBN: $0-201-50648-3$ \\
\hline P.O. Box 1922 & $\$ 51.75$ \\
\hline \multicolumn{2}{|l|}{ Santa Barbara, CA 93116-1922 } \\
\hline \multirow[t]{2}{*}{$\$ 85$} & Student SYSTAT \\
\hline & Course Technology, Inc. \\
\hline MultiStat & One Main St. \\
\hline Biosoft & Cambridge, MA 02142 \\
\hline PO Box 10938 & ISBN: $1-878748-95-5$ \\
\hline Ferguson, MO 63135-9913 & $\$ 37.50$ \\
\hline \multicolumn{2}{|l|}{$\$ 99($ minimum of 10$)$} \\
\hline \multicolumn{2}{|l|}{ MYSTAT } \\
\hline \multicolumn{2}{|l|}{ Course Technology, Inc. } \\
\hline \multicolumn{2}{|l|}{ One Main St. } \\
\hline \multicolumn{2}{|l|}{ Cambridge, MA 02142} \\
\hline \multicolumn{2}{|l|}{ ISBN: $1: 878748-62-9$} \\
\hline$\$ 18$ & \\
\hline (also bundled with some texts) & \\
\hline
\end{tabular}

(Manuscript received January 11, 1994;

revision accepted for publication July 11, 1994.) 